\title{
PENGARUH PEMBERIAN KOMPRES HANGAT SUPRAPUBIK TERHADAP PEMULIHAN REFLEK VESICA URINARIA PADA PASIEN POST SPINAL ANESTESI DI RSU PKU MUHAMMADIYAH BANTUL
}

\author{
Winda Arfian Sari*, Rosa Delima Ekwantini, Agus Sarwo Prayogi* \\ Jurusam Keperawatan Poltekkes Kemenkes Yogyakarta \\ Email : windaarfian@gmail.com, saworbali@gmail.com
}

\begin{abstract}
Spinal anesthesia causes urinary retention because the urethral sphincter muscle doesn't respond to urination desire. When circumstances continue the pressure inhibits the flow of urine occurs hydroureter, hydronephrosis and gradually kidney failure. Suprapubic warm compresses activated dopaminergic transmission in the mesolimbic central nervous system that effectively improve circulation speeds recovery of vesica urinary reflex. This research is aimed to know the effect of warm compress on the vesica urinaria recovery reflex in post spinal anesthesia patient at RS PKU Muhammadiyah Bantul. This study was an experimental study with quasy experiment type with Non Equivalent Control Group After Only Design. The treatment provided was suprapubic warm compress. Consecutive sampling with 40 respondents divided into control and intervention group that undergo spinal anesthesia at RSU PKU Muhammadiyah Bantul. Data analysis was done by Chi square. In control group, 9 respondents (45\%) had vesica urinary reflex recovery $\leq 8$ hours, while in intervention group, 16 respondents (20\%) had vesica urinary reflex $\leq 8$ hours. Chi Square test resulted on $p$ value $0.022(\leq 0,05)$. There is an effect of suprapubic warm compress toward vesica urinary reflex recovery in post spinal anesthesia patients at RSU PKU Muhammadiyah Bantul.
\end{abstract}

Keywords: Warm Compress, Vesica Urinaria Recovery

\section{ABSTRAK}

Spinal anestesi menyebabkan retensi urin karena otot sfingter uretra tidak merespon keinginan berkemih. Bila keadaan berlanjut tekanan menghambat aliran urin terjadilah hidroureter, hidronefrosis dan lambat laun gagal ginjal. Kompres hangat suprapubik mengaktivasi transmisi dopaminergik dalam mesolimbik sistem saraf pusat sehingga efektif meningkatkan sirkulasi mempercepat pemulihan reflek vesica urinaria pasca pembedahan. Penelitian ini bertujuan agar diketahuinya pengaruh pemberian kompres hangat terhadap pemulihan reflek vesica urinaria pada pasien post spinal anestesi di RSU PKU Muhammadiyah Bantul. Penelitian ini merupakan penelitian eksperimental dengan jenis quasy eksperiment dengan Non Equivalent Control Group After Only Design. Perlakuan yang diberikan adalah kompres hangat suprapubik. Pengambilan sampel consecutive sampling dengan jumlah 40 responden terbagi menjadi kelompok kontrol dan intervensi yang menjalani spinal anestesi di RSU PKU Muhammadiyah Bantul. Analisis data dilakukan dengan Chi square. Responden kelompok kontrol terdapat 9 responden (45\%) yang pemulihan reflek vesika urinaria $\leq 8$ jam, sementara kelompok intervensi terdapat 16 responden (20\%) pemulihan reflek vesika urinaria $\leq 8$ jam. Hasil uji Chi Square diketahui nilai $p$ value 0,022 ( $\leq 0,05$ ). Ada pengaruh pemberian kompres hangat suprapubik terhadap pemulihan reflek vesika urinaria pada pasien post spinal anestesi di RSU PKU Muhammadiyah Bantul

Kata Kunci : Kompres Hangat, Pemulihan Vesica Urinaria

\section{PENDAHULUAN}

Proses pembedahan memerlukan upaya untuk menghilangkan nyeri, keadaan itu disebut anestesi. Anestesi dibagi menjadi anestesi umum dan anestesi regional. Obat dan teknik anestesi pada umumnya dapat mengganggu fungsi nafas, peredaran darah dan sistem saraf. Analgesik narkotik dan anestesi dapat memperlambat laju filtrasi glomerolus dan mengurangi haluaran urin. Obat farmakologi juga merusak impuls sensorik dan motorik yang berjalan diantara kandung kemih, medula spinalis, dan otak'.

Klien yang pulih dari anestesi dan analgetik seringkali tidak mampu merasakan bahwa kandung kemihnya penuh dan tidak mampu memulai atau menghambat berkemih. Spinal blok anestesi terutama menimbulkan retensi urin, karena akibat anestesi ini, klien tidak mampu merasakan adanya kebutuhan untuk berkemih dan kemungkinan otot kandung kemih dan otot sfingter juga tidak mampu merespon terhadap keinginan berkemih ${ }^{2}$.

insiden retensi urin setelah anestesi dan pembedahan berkisar antara $5 \%$ hingga $70 \%$. Insiden yang lebih tinggi dari Post Operative Urin Retention (POUR) terjadi pada pria $(4,7 \%)$ dibandingkan dengan perempuan $(2,9 \%)$. Dalam sebuah survei tindak lanjut nasional di Swedia, ahli anestesi melaporkan insiden lebih besar dengan epidural morfin (38\%) dibandingkan dengan morfin intratekal 
$(13 \%)^{3}$.

Anestesi spinal lebih signifikan menyebabkan retensi urin dibandingkan dengan anestesi umum, 44 $\%$ dari pasien pasca pembedahan dengan anestesi spinal memiliki volume kandung kemih lebih $500 \mathrm{ml}$ (retensi urin) dan 54\% tidak memiliki gejala distensi kandung kemih ${ }^{4}$.

Akibat lanjut retensi urin, buli-buli akan mengembang melebihi kapasitas maksimal sehingga tekanan di dalam lumen dan tegangan dari dindingnya akan meningkat. Bila keadaan ini dibiarkan berlanjut, tekanan yang meningkat di dalam lumen akan menghambat aliran urin dari ginjal dan ureter sehingga terjadi hidroureter dan hidronefrosis dan lambat laun terjadi gagal ginjal. Retensi urin juga menjadi penyebab terjadinya infeksi saluran kemih (ISK) dan bila ini terjadi dapat menimbulkan gawat yang serius seperti pielonefritis dan urosepsis ${ }^{5}$.

Beberapa tindakan pencegahan retensi urin pasca spinal anestesi adalah membatasi asupan cairan, mobilisasi dini, kompres hangat di supra pubik, dan penggunaan obat anestesi spinal "short-acting"6. Kompres hangat di supra pubik, pemberian obat kolinergik, manuver crede, dan pemasangan kateter merupakan tindakan yang dilakukan untuk mengatasi retensi urin ${ }^{7}$.

Berdasarkan penelitian yang di RS PKU Muhammadiyah Yogyakarta didapatkan angka kejadian ISK pada pasien yang dipasang kateter urin sebanyak $20 \%$ dari 30 pasien. Oleh karena itu, diperlukan suatu manajemen untuk mengurangi risiko retensi urin, salah satunya dengan merangsang refleks vesika urinaria dalam fungsi berkemih dengan kompres hangat pada pasien post spinal anestesi ${ }^{8}$.

Kompres hangat dengan suhu $45^{\circ} \mathrm{C}-50,5^{\circ} \mathrm{C}$ dapat dilakukan dengan menempelkan kantung karet yang diisi air hangat ke daerah tubuh yang nyeri. Secara fisiologis, respon tubuh terhadap panas yaitu meningkatkan metabolisme jaringan dan permeabilitas kapiler. Respon dari panas inilah yang dipergunakan untuk keperluan terapi pada berbagai kondisi dan keadaan yang terjadi dalam tubuh ${ }^{9}$.

Berdasarkan hasil catatan medik di RS PKU Muhammadiyah Bantul, Instalasi Bedah Sentral (IBS) di RS PKU Muhammadiyah Bantul rata-rata pasien yang melakukan operasi dalam satu bulan sebanyak 300 hingga 400 pasien, 100 diantaranya menjalani operasi elektif dengan regional anestesi (RA) teknik subarahnoid block (SAB). RA tersebut dengan teknik SAB sebesar $96,83 \%$ dan teknik epidural $3,17 \%$. Kateter urin dipasang di ruang pembedahan apabila pasien dilakukan anestesi spinal pada operasi elektif. Pelepasan kateter urin dilakukan setelah 24 jam pasca operasi atau tergantung dari kondisi pasien itu sendiri. Berdasarkan hasil wawancara dengan perawat bedah di RSU PKU Muhammadiyah Bantul, Post Operative Urin Retention (POUR) terjadi pada 5 dari 10 pasien yang menjalani operasi dengan jenis RA. Tujuan Penelitian ini pengaruh pemberian kompres hangat terhadap waktu pemulihan vesica urinaria pada pasien dengan post spinal anestesi.

\section{METODE}

Jenis penelitian yang digunakan adalah penelitian quasy eksperimen. Desain yang digunakan adalah nonequivalent control group afteronly.

Tabel 1. Desain Penelitian

\begin{tabular}{lcc}
\hline & Perlakuan & Post test \\
\hline Intervensi & $\mathrm{X}$ & $\mathrm{O} 1$ \\
\hline Kontrol & & $\mathrm{O} 2$ \\
\hline
\end{tabular}

Keterangan:

$X$ : Perlakuan

01: Observasi kelompok intervensi

O2: Observasi kelompok kontrol

Penelitian dilakukan satu jam setelah pasien berada di ruang rawat inap bedah, kelompok intervensi dilakukan bladder training dan dilakukan pemberian kompres hangat suprapubik selama 20 menit dengan suhu $45^{\circ} \mathrm{C}-50,5^{\circ} \mathrm{C}$, sedangkan kelompok kontrol hanya dilakukan blader training. Kedua kelompok dinilai berapa lama waktu yang dibutuhkan untuk merasakan keinginan berkemih, dilakukan pelepasan bladder training apabila sudah ada keinginan berkemih dan setiap satu jam pada kelompok intervensi maupun kelompok kontrol walaupun belum merasakan keinginan untuk berkemih.

Sampel penelitian yaitu pasien post spinal anestesi di RSU PKU Muhammadiyah Bantul. Sampel diambil secara consecutive sampling dengan krteria inklusi: bersedia menjadi responden dengan adanya informed consent, menjalani operasi elektif, berusia 17 tahun 55 tahun, status fisik ASA I dan II, menggunakan obat anestesi bupivacain, mampu berkomunikasi verbal dengan baik serta dengan kriteria eksklusi: pasien dirawat diruang intensive care, tidak bersedia menjadi responden dan terdapat luka/kerusakan kulit di area suprapubik. Besar sampel sebanyak 40 dengan masing-masing 20 setiap kelompok yang diperoleh dari rumus penghitungan sampel. Data hasil penelitian kemudian diuji dengan analisis univariat deskriptif dan uji bivariat (chi square test).

\section{HASIL DAN PEMBAHASAN}

Analisis data dalam penelitian ini meliputi karakteristik responden, distribusi frekuensi, serta analisis korelasi pengaruh pemberian kompres hangat terhadap pemulihan vesica urinaria pada pasien dengan post spinal anestesi. 


\section{Karakteristik Responden}

Tabel 2. Distribusi Frekuensi Karakteristik Responden

\begin{tabular}{|c|c|c|c|c|}
\hline \multirow{2}{*}{ Variabel } & \multicolumn{2}{|c|}{ Intervensi } & \multicolumn{2}{|c|}{ Kontrol } \\
\hline & $\mathbf{F}$ & $\%$ & $f$ & $\%$ \\
\hline \multicolumn{5}{|l|}{ Jenis Kelamin: } \\
\hline $\mathrm{L}$ & 12 & 60.0 & 18 & 90.0 \\
\hline $\mathrm{P}$ & 8 & 40.0 & 2 & 10.0 \\
\hline \multicolumn{5}{|l|}{ Umur (tahun): } \\
\hline $17-25$ & 4 & 20.0 & 1 & 5.0 \\
\hline $26-35$ & 1 & 5.0 & 2 & 10.0 \\
\hline $36-45$ & 6 & 30.0 & 4 & 20.0 \\
\hline $46-55$ & 9 & 45.0 & 13 & 65.0 \\
\hline \multicolumn{5}{|l|}{ ASA: } \\
\hline 1 & 15 & 75.0 & 11 & 55.0 \\
\hline II & 5 & 25.0 & 9 & 45.0 \\
\hline \multicolumn{5}{|l|}{ Jenis Bedah: } \\
\hline Urologi & 7 & 35.0 & 13 & 65.0 \\
\hline Orthopedi & 3 & 15.0 & 1 & 5.0 \\
\hline Bedah Umum & 10 & 50.0 & 6 & 30.0 \\
\hline \multicolumn{5}{|c|}{ Lama Operasi: } \\
\hline$\leq 60$ menit & 19 & 95.0 & 19 & 95.0 \\
\hline$>60$ menit & 1 & 5.0 & 1 & 5.0 \\
\hline
\end{tabular}

Berdasarkan tabel 2 dilihat dari jenis kelamin, kedua kelompok memiliki jumlah terbanyak responden berjenis kelamin laki-laki. Ditinjau dari pengelompokkan usia, kedua kelompok dengan usia terbanyak pada rentang 46-55 tahun. Status fisik ASA masih sama antara kedua kelompok yaitu terbanyak dengan ASA I dengan total 26 dari 40 responden. Walau memiliki persamaan jumlah terbanyak karakteristik jenis kelamin, umur dan ASA, namun jumlah masing-masing karakterisstik berbeda. Karakteristik jenis bedah lebih terlihat perbedaannya, kelompok kontrol lebih banyak dengan kasus bedah urologi sedangkan kelompok intervensi lebih banyak pada kasus bedah umum.

2. Pemulihan Reflek Vesica Urinaria

Tabel 3 Distribusi Responden Menurut Waktu Pemulihan Reflek Vesica Urinaria

\begin{tabular}{ccccc}
\hline $\begin{array}{c}\text { Pemulihan } \\
\text { Reflek } \\
\text { Vesica } \\
\text { Urinaria }\end{array}$ & \multicolumn{2}{c}{$\begin{array}{c}\text { Kelompok } \\
\text { kontrol }\end{array}$} & \multicolumn{2}{c}{$\begin{array}{c}\text { Kelompok } \\
\text { intervensi }\end{array}$} \\
\cline { 2 - 5 } & $\mathrm{F}$ & $\%$ & $\mathrm{f}$ & $\%$ \\
\hline $\mathbf{8}$ jam & 9 & 45 & 16 & 80 \\
$>\mathbf{8}$ jam & 11 & 55 & 4 & 20 \\
\hline Total & 20 & 100 & 20 & 100 \\
\hline
\end{tabular}

Berdasarkan tabel 3 bahwa responden dengan spinal anestesi pada kelompok kontrol yang berjumlah 20 responden terdapat 11 responden $(55 \%)$ yang pemulihan reflek vesika urinarianya $>$ 8 jam dan 9 responden (45\%) sisanya memiliki waktu pemulihan reflek normal atau $\leq 8$ jam, sementara itu responden dengan spinal anestesi pada kelompok intervensi terdapat 16 responden $(80 \%)$ yang pemulihan reflek vesika urinarianya $\leq 8$ jam dan 4 responden (20\%) lainnya memiliki waktu pemulihan reflek lebih lama atau $>8$ jam. Berdasarkan tabel ini dapat dikatakan bahwa responden dengan pemberian kompres hangat memiliki waktu pemulihan reflek vesica urinaria yang normal.

Ada beberapa faktor yang mempengaruhi kemampuan klien dalam berkemih diantaranya diet dan asupan, respon keinginan awal untuk berkemih, gaya hidup, stress psikologis, tingkat aktifitas, usia, kondisi penyakit, tonus otot dan pengobatan ${ }^{2}$. Kemungkinan penyebab lamanya timbul reflek berkemih bila dicocokkan diantara faktor tersebut yang pasti terjadi pada pasien pre operasi adalah stress psikologis, kondisi penyakit, usia dan pengobatan. Faktor usia, didukung pula berdasarkan data analisa karakteristik responden pada kelompok kontrol sebagian besar responden yaitu sebanyak 13 responden $(65 \%)$ dengan rentang usia 46-55 tahun atau fase masa lansia awal selain itu untuk faktor jenis penyakit, jenis bedah dominan pada kelompok kontrol adalah bedah urologi sebesar 13 responden (65\%).

Faktor resiko terjadinya Post Operative Urine Retention (POUR) meliputi usia dan jenis kelamin, jenis operasi, komorbiditas, obat anestesi, cairan IV serta lama operasi ${ }^{2}$. Usia, jenis kelamin, kecemasan, riwayat POUR sebelumnya, jenis dan durasi operasi, pemberian cairan pasca operasi, jenis anestesi dan jenis obat-obatan selama operasi merupakan faktor resiko terjadinya POUR $^{10}$.

Ditinjau kembali dari faktor usia dan jenis kelamin, $65 \%$ responden memasuki fase lansia awal (46-55 tahun) dan $60 \%$ responden berjenis kelamin laki-laki. Usia berpengaruh terhadap reflek vesika urinaria karena semakin tua usia maka semakin rentan mengalami degenerasi neuron sehingga menyebabkan disfungsi vesika urinaria. Jenis kelamin juga berpengaruh terhadap reflek vesika urinaria, ditinjau dari struktur anatomi uretra, panjang uretra perempuan lebih pendek yaitu $3,7 \mathrm{~cm}$ sedangkan laki-laki mencapai panjang hingga $20 \mathrm{~cm}$, sehingga pada pria lebih beresiko mengalami retensi urin.

POUR telah terbukti meningkat seiring bertambahnya usia, dengan risikonya meningkat 2,4 kali pada pasien berusia di atas 50 tahun. Kejadian POUR telah dilaporkan lebih tinggi pada pria $(4,7 \%)$ dibandingkan wanita $(2,9 \%)^{3}$. Jenis kelamin laki-laki, usia > 50 tahun, dan operasi di area abdomen meningkatkan resiko terjadinya POUR ${ }^{11}$.

3. Uji Chi Square 
Tabel 4. Uji Chi Square test Pengaruh Pemberian Kompres Hangat Suprapubik terhadap Pemulihan Reflek Vesica Urinaria

\begin{tabular}{|c|c|c|c|c|c|}
\hline \multirow{3}{*}{$\begin{array}{c}\text { Pemberian } \\
\text { Kompres } \\
\text { Hangat } \\
\text { Suprapubik }\end{array}$} & \multicolumn{4}{|c|}{$\begin{array}{c}\text { Pemulihan } \\
\text { Reflek Vesica } \\
\text { Urinaria }\end{array}$} & \multirow{3}{*}{$\begin{array}{c}\begin{array}{c}\text { Nilai } \\
\text { asym.sig } \\
(2 \text { sided })\end{array} \\
p\end{array}$} \\
\hline & \multicolumn{2}{|c|}{$=8 \mathrm{jam}$} & \multicolumn{2}{|c|}{$>8$ jam } & \\
\hline & $f$ & $\%$ & $f$ & $\%$ & \\
\hline $\begin{array}{l}\text { Kelompok } \\
\text { kontrol }\end{array}$ & 9 & 45 & 11 & 55 & \multirow{2}{*}{0,022} \\
\hline $\begin{array}{l}\text { Kelompok } \\
\text { intervensi }\end{array}$ & 16 & 80 & 4 & 20 & \\
\hline
\end{tabular}

Berdasarkan hasil pada tabel 4, diketahui pemulihan reflek vesika urinaria pada pasien post operasi dengan spinal anestesi yang dilakukan kompres hangat di ruang rawat inap bedah umum RSU PKU Muhammadiyah Bantul Yogyakarta sebanyak 16 responden $(80 \%)$ yang pemulihan reflek vesika urinarianya $\leq 8$ jam dan 4 responden $(20 \%)$ lainnya memiliki waktu pemulihan reflek lebih lama atau > 8 jam.

Apabila ditinjau dari data analisa karakteristik responden pemberian kompres hangat suprapubik pada kelompok intervensi atau yang dilakukan pemberian kompres hangat, maka dari karakter rentang usia paling banyak sama dengan kelompok kontrol yaitu pada usia 46-55 tahun atau lansia awal sebanyak 9 responden (45\%), jumlah ini lebih sedikit $20 \%$ dari kelompok kontrol. Nilai $p$ juga menunjukkan 0,028 yang berarti varian tidak sama. Karakteristik jenis bedah yang terbanyak pada kelompok intervensi adalah bedah umum yaitu sebanyak 10 responden (50\%). Status fisik operasi ASA I sebanyak 15 responden $(75 \%)$. Perbedaan karakteristik responden pada kedua kelompok tersebut kemungkinan memberikan pengaruh pemulihan reflek vesika urinaria dari faktor usia dan kondisi penyakit responden.

Cepatnya proses berkemih pada pasien yang diberikan kompres hangat karena terapi kompres hangat dapat meningkatkan dan memperlancar sirkulasi. Kompres hangat yang lembab efektif dapat memberikan stimulus sensorik yang dapat membantu klien untuk relaksasi otot abdomen. Keberhasilan kompres hangat dapat mempercepat pemulihan pasca pembedahan ${ }^{7}$.

Beberapa tindakan pencegahan terjadinya retensi urin pasca spinal anestesi meliputi mobilisasi dini, membatasi asupan cairan, kompres hangat di suprapubik dan penggunaan obat anestesi "short-acting"6, sementara itu intervensi keperawatan untuk mencegah POUR yaitu membuat pasien kencing sebelum operasi agar mereka bisa memasuki ruang operasi dengan kandung kemih yang kosong, menghidupkan keran yang cukup dekat untuk didengar agar membuat lebih nyaman serta membantu otot perineum pasien menjadi rileks, memberikan kompres kantong air panas ke daerah suprapubik pasien, serta membantu pasien agar melakukan mobilisasi dini ${ }^{10}$.

Hasil pengujian statistik antara kedua variabel dengan pengolahan data dengan menggunakan uji Chi square menunjukkan nilai $p$ value 0,022 . Nilai a yang digunakan dalam penelitian ini yaitu 0,05 . Jika $p \leq 0,05$ maka Ho ditolak. Hasil dalam penelitian ini diperoleh $0,022 \leq 0,05$. Hasil tersebut mengartikan bahwa ada pengaruh pemberian kompres hangat suprapubik terhadap pemulihan reflek vesika urinaria pada pasien post operasi dengan spinal anestesi di ruang rawat inap bedah RSU PKU Muhammadiyah Bantul Yogyakarta karena $p$ value lebih kecil dari 0,05.

Adanya perbedaan lama waktu timbul reflek vesica urinaria pada pasien post operasi dengan spinal anestesi kelompok intervensi dan kontrol dapat disebabkan karena adanya perlakuan kompres hangat, spinal blok anestesi terutama menimbulkan retensi urin, karena akibat anestesi ini, klien tidak mampu merasakan adanya kebutuhan untuk berkemih dan kemungkinan otot kandung kemih dan otot sfingter uretra juga tidak mampu merespon terhadap keinginan berkemih ${ }^{2}$.

Pemberian kompres hangat dilakukan dengan menggunakan buli-buli panas atau kantong air panas terjadi pemindahan panas secara konduksi dari buli-buli sehingga akan menyebabkan pelebaran pembuluh darah dan akan terjadi penurunan ketegangan otot ${ }^{12}$.

Kompres hangat memiliki beberapa pengaruh yaitu melebarkan pembuluh darah dan memperbaiki peredaran darah didalam jaringan, efek kompres hangat pada otot dapat menurunkan ketegangan serta dilatasi pembuluh darah yang mengakibatkan peningkatan sirkulasi darah serta pembuluh kapiler. Efek ini diharapkan akan menyebabkan dilatasi arteriol aferen dan meningkatkan aliran darah ke dalam glomerulus sehingga meningkatkan GFR. Spinal anestesi menurunkan 5-10\% GFR, sehingga dari pemberian kompres hangat ini diharapkan dapat meningkatkan GFR untuk membantu haluaran urin $^{13}$.

Efek pemberian kompres hangat terhadap tubuh dapat menyebabkan vasodilatasi pembuluh darah dan meningkatkan sirkulasi. Adanya peningkatan aliran darah ini akan meningkatkan proses metabolisme dari sisa obat anestesi yang masih tertinggal dalam sirkulasi sehingga dapat mengurangi efek obat anestesi. Dengan adanya penurunan efek obat anestesi tersebut maka dapat mengembalikan impuls sensorik dan motorik yang berjalan diantara kandung kemih, medula spinalis, dan otak sehingga dapat menimbulkan adanya 
reflek vesika urinaria ${ }^{1}$.

Pemakaian kompres hangat biasanya hanya dilakukan setempat saja pada bagian tubuh tertentu. Dengan pemberian panas dari kompres hangat, pembuluh-pembuluh darah melebar sehingga akan memperlancar peredaran darah didalam jaringan tersebut. Panas cukup berguna untuk pengobatan, meningkatkan aliran darah ke bagian yang cedera. Apabila panas digunakan selama 1 jam atau lebih maka aliran darah akan menurun akibat refleks vasokontriksi karena tubuh berusaha mengontrol kehilangan panas dari area tersebut. Pengangkatan dan pemberian kembali panas lokal secara periodik akan mengembalikan efek vasodilatasi ${ }^{9}$.

Adanya perbedaan lama waktu timbul reflek vesica urinaria pada pasien post operasi dengan spinal anestesi kelompok intervensi dan kontrol lainnya dapat disebabkan karena adanya faktor karakteristik responden yang mempengaruhi, diantaranya usia, jenis kelamin, dan status fisik ASA. Usia $>50$ tahun mengalami peningkatan resiko POUR 2,4 kali lebih tinggi daripada usia $<50$ tahun. Pria lebih tinggi resiko mengalami pemanjangan waktu muncul reflek berkemih yaitu $4,7 \%$ dibandingkan wanita $2,9 \%$. Status fisik pasien (ASA) berpengaruh terhadap pemulihan reflek vesika urinaria, pasien dengan hipertensi dan yang menerima analgetik opiat serta epidural meningkatkan resiko terjadinya POUR ${ }^{11}$.

Waktu tercepat yang dibutuhkan untuk pemulihan reflek vesika urinaria pada kelompok intervensi tercatat 5 jam, sementara itu waktu terlama pada kelompok intervensi membutuhkan 7 jam dan waktu pemulihan reflek vesika urinaria rata-rata pada kelompok intervensi yaitu 6,35 jam. Waktu yang dibutuhkan pada pasien post spinal anestesi untuk kembali memiliki kontrol volunter berkemih yaitu $7-8$ jam3. Kelompok kontrol memiliki sebanyak 11 responden dengan waktu pemulihan reflek vesica urinaria $>8 \mathrm{jam}$. Hal ini menandakan bahwa pemberian kompres hangat suprapubik cukup efektif untuk membantu mempercepat pengembalian reflek vesika urinaria.

\section{KESIMPULAN}

Hasil penelitian menunjukkan ada pengaruh pemberian kompres hangat suprapubik terhadap pemulihan reflek vesica urinaria pada pasien post spinal Anestesi di RSU PKU Muhammadiyah Bantul, dengan hasil uji nilai $p=0,022<0,05$. Antara kelompok intervensi dengan kelompok kontrol. Dengan demikian hasil penelitian ini dapat digunakan sebagai pertimbangan tindakan keperawatan untuk mencegah terjadinya retensi urin dan memberikan rasa nyaman pada pasien post spinal anestesi.

\section{SARAN}

Diharapkan hasil penelitian ini dapat digunakan sebagai intervensi keperawatan dan non farmakologi pada pasien post operasi dengan spinal anestesi khususnya ruang rawat inap bedah sebagai tindakan asuhan keperawatan mandiri Bagi peneliti selanjutnya diharapkan dapat meminimalisir kelompok varian responden dan berfokus pada salah satu jenis bedah saja serta melakukan pengendalian dan penghitungan asupan cairan kebutuhan responden.

\section{DAFTAR PUSTAKA}

1. Sjamsuhidajat \& Jong, W. (2005). Buku Ajar IImu Bedah (2nd Ed). Jakarta : EGC

2. Mulroy, M. F., Bernard, C. M., McDonald, S. B., \& Salinas, F. V. (2009). A Practical Approach To Regional Anesthesia (4th Ed). Wolters Kluwer Health

3. Baldini, G. (2009). Postoperative Urinary Retention Anesthetic and Perioperative Consideration. Journal of Anesthesiology, 5 2009, Vol.110, 11391157. doi:10.1097/ALN.0b013e31819f7aea

4. Hasanah, R. (2013). Pengaruh Mobilisasi Dini Terhadap Pemulihan Fungsi Kandung Kemih ( $\mathrm{skripsi}$ ). Retrieved from http://digilib.unmuhjember.ac.id/files/disk1/70/umj -1x-roifatulha-3478-1-manuskrip.pdf.

5. Gardjito, W. (2000). Retensio Urine Permasalahan dan Penanganannya. Lab/UPF IImu Bedah. FK Unair/RSUD Dr. Soetomo Surabaya

6. Akhrita, Z. (2011). Pengaruh Mobilisasi Dini Terhadap Pemulihan Kandung Kemih Pasca Pembedahan dengan Anestes Spinal di IRNA B (Bedah Umum) RSUP Dr.M Djamil Padang ( $\mathrm{skripsi}$ ). Retrieved from http://repository.unand.ac.id/

7. Kozier, B., Erb, G., \& Berman, A. (2010). Buku Ajar Fundamental Keperawatan: Konsep, Proses, \& Praktik (7th ed). Jakarta: EGC

8. Afsah. R. (2008). Tingkat Kejadian ISK Pada Pasien Dengan Kateter Urin di RS PKU Muhammadiyah Yogyakarta (Skripsi).Retrieved fromhttp://repository.umy.ac.id/bitstream/handle/1 23456789/5766/bab\%20i.pdf?sequence=2\&isAllo wed $=y$

9. Potter \& Perry. (2010). Fundamental Keperawatan (7th ed). Singapore : Elsevier, Publikasi Salemba Medika

10.Simsek, Y. Z dan Surreya, K. (2016). Postoperative Urinary Retention and Nursing Approaches. International Journal of Caring Sciences September - December 2016 Volume 9. Issue 3 Page 1157

11.Steggall, M et a.l (2013). Post-Operative Urinary Retention. Nursing Standart Jounal. 2013 Oct 2- 
$8 ; 28(5): 43-8$. doi:10.7748/ns2013.10.28.5.43.e792

12.Kusmiyati, Y., dkk. (2009). Perawatan Ibu Hamil. Yogyakarta : Fitramaya Mulroy, M. F., Bernard, C. M., McDonald, S. B., \& Salinas, F. V. (2009). A Practical Approach To Regional Anesthesia (4th Ed). Wolters Kluwer Health
13.Morgan, G. E., Mikhail, M.S., \& Murray, M.J. (2006). Clinical Anesthesiology 4th edition. USA: Lange Medical Books

14.Elsamra, S. E. \& Ellsworth, P. (2012). Effects of Analgesic and Anesthetics Medications on Lower Urinary Tract Function. Urologic Nursing Journal, March-April 2012 / Volume 32 Number 232 (2), 60-68 